\title{
Maatilatalousyrittäjien hevostapaturmat
}

Päivi Lamminen ${ }^{1)}$, Anu Hilli ${ }^{1)}$, Tiina Greus ${ }^{1)}$

Sähköposti: etunimi.sukunimi@ oamk.fi,

1), Oulun seudun ammattikorkeakoulu, luonnonvara-alan yksikkö, Oulu, etunimi.sukunimi@oamk.fi

\section{Tiivistelmä}

Vuonna 2007 Suomessa oli 68000 hevosta ja määrä kasvaa noin tuhannella eläimellä vuodessa. Hevosmäärän kasvaessa on tärkeää miettiä hevostapaturmien ehkäisykeinoja. Kaikilla uusilla hevosenomistajilla ei ole tarpeeksi tietoa eikä kokemusta hevosen asiantuntevasta käsittelystä ja hoidosta.

Tutkimuksen tarkoituksena oli tarkastella Maatalousyrittäjien eläkelaitoksen vakuuttamille yrittäjille tapahtuneita hevosonnettomuuksia vuosilta 1997-2006. Hevosonnettomuuksista pyrittiin selvittämään, millainen on keskimääräisen loukkaantuneen profiili. Lisäksi mietittiin, minkälaisia asioita pitäisi ottaa huomioon tapaturmien ehkäisemiseksi.

Tulosten mukaan tapaturmista $75 \%$ aiheutti hevonen ja siinä loukkaantuivat tavallisimmin yläja alaraajat. Hevostapaturmissa loukkaantuneista oli miehï $58 \%$ ja iältään he olivat 51-60-vuotiaita, naisten loukkaantumisista suurin osa tapahtui 31-40-vuotiaille. Yleisimmät vammat olivat sijoiltaan menot, venähdykset ja nyrjähdykset. Tapaturmista $21 \%$ tapahtui hevosten valjastuksen, siirtojen ja kuljetusten yhteydessä.

Hevostapaturmat ovat monen tapahtuman yhdistelmä. Tapaturmien välttämiseksi hevosen käsittelyyn ja kuljetuksiin tulee varata riittävästi aikaa ja tutustua hevosen ominaisuuksiin. Hevonen toimii vaistojen ja kokemusten varassa. Ihmisen vastuulla on riskitilanteiden ja vaarojen havaitseminen sekä niiden poistaminen. Oma rauhallinen asenne ja hyvin koulutetut hevoset ovat myös turvallisuuteen vaikuttavia asioita.

Avainsanat: hevonen, maatila, turvallisuus, tapaturma 


\section{Johdanto}

EU-jäsenyyden aikana Suomessa on aktiivisten maatilojen määrä vähentynyt kolmanneksella. Tilat, joiden tuotantosuuntana on hevostalous, ovat kuitenkin lisääntyneet samalla kun muiden kotieläintilojen määrä on vähentynyt (Tiilikainen 2004, Niiranen 2008). Vuonna 2007 Suomessa oli 68000 hevosta (Suomen Hippos 2008), joista noin puolet on maatiloilla. Maatilatalousyrittäjien lakisääteisiä työeläke- ja työtapaturmavakuutuksia hoitaa Maatalousyrittäjien eläkelaitos (Mela). Se rekisteröi vakuuttamiensa maatilatalousyrittäjien hevostapaturmat. Hevosten määrä on kasvanut aina 1990-luvulta lähtien (Suomen Hippos 2008). Hevosmäärän kasvaessa maatiloilla voivat maatilatalousyrittäjien hevostapaturmat lisääntyä. Tapaturmista aiheutuu loukkaantumisen lisäksi myös taloudellisia menetyksiä yrittäjälle sekä Melalle.

Tutkimuksessa selvitettiin syitä hevostapaturmiin. Tarkoituksena oli selvittää yleisimmät tapaturmien ja loukkaantumisten aiheuttajat maatilatalousyrittäjille heidän toimiessaan hevosten kanssa sekä vammat ja niiden laadut. Tutkimus toi uutta tietoa hevosten kanssa tapahtuvista tapaturmista, sillä aiheesta ei ole aikaisempaa tutkimustietoa.

\section{Aineisto ja menetelmät}

Aineistona käytettiin Maatalousyrittäjien eläkelaitoksen rekisteröimiä maatilatalousyrittäjille tapahtuneita hevostapaturmia vuosilta 1997-2006. Tapaturmista oli tilastoitu tapaturman sattumisvuosi, työtehtävä, jossa tapaturma aiheutui, tapaturmanaiheuttaja ja vahingoittunut kehon osa. Lisäksi oli rekisteröity viikonpäivä, jolloin tapaturma sattui ja päivärahajakson pituus päivissä tai eläkejakson pituus päivissä, jos tapaturma aiheutti lyhyttä tai pidempiaikaista työkyvyttömyyttä. Myös loukkaantuneen henkilön ikä ja sukupuoli oli koottu tiedostoon. Maatilatalousyrittäjille oli tapahtunut hevostapaturmia 1506 kappaletta kymmenessä vuodessa.

\section{Tulokset}

Tulokset osoittavat, että maatilatalousyrittäjien hevostapaturmat ovat lisääntymässä. Vuonna 1997 hevosten aiheuttamia tapaturmia oli $163 \mathrm{kpl} \mathrm{ja} \mathrm{vuonna} 2006$ niitä oli $186 \mathrm{kpl}$ (Kuva 1).

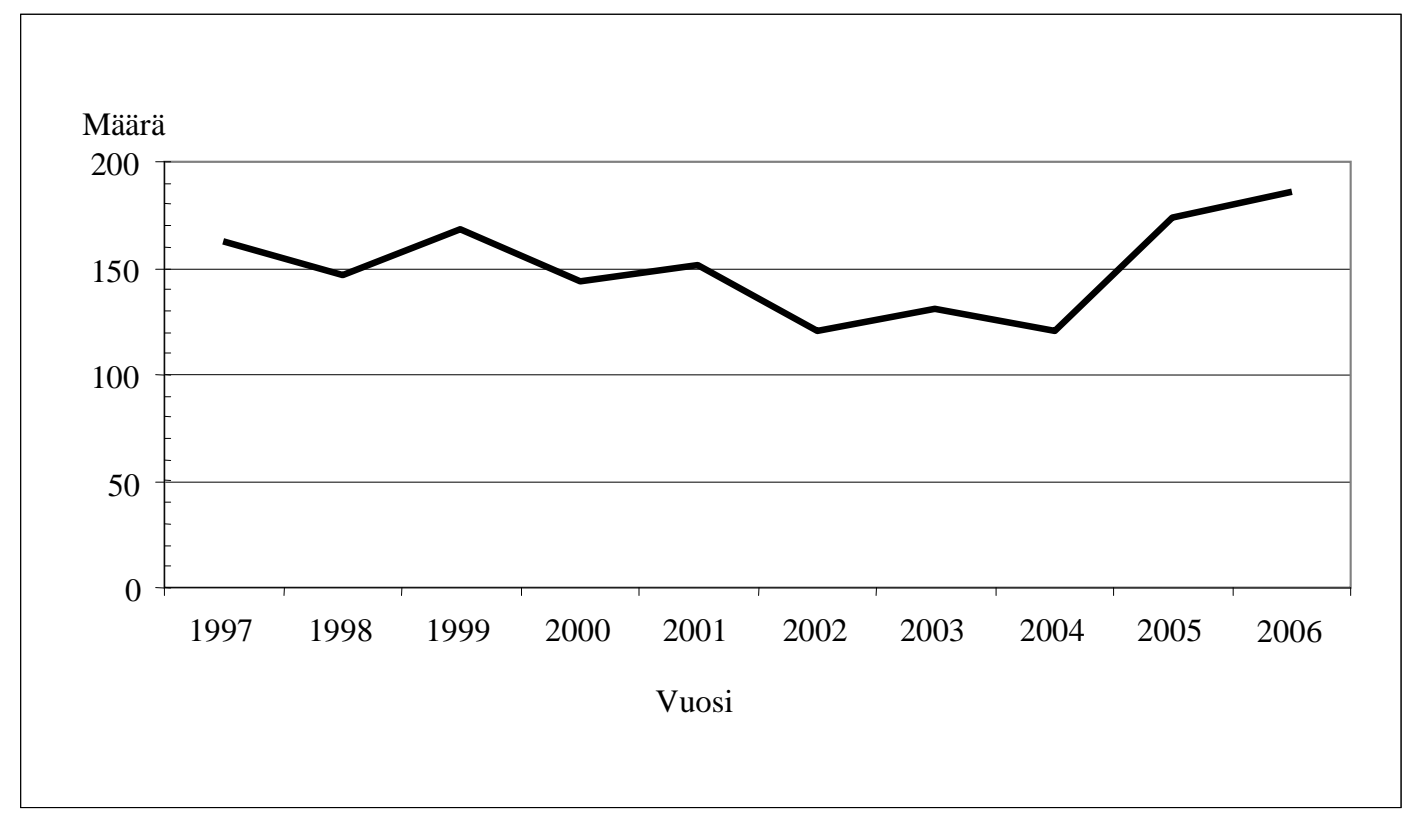

Kuva 1. Hevostapaturmien määrän kehitys 1997-2006. 
Hevoset aiheuttivat noin $75 \%$ tapaturmissa syntyneistä vammoista ja noin $9 \%$ tapaturmista aiheutui ulkoisesta ympäristöstä, esimerkiksi kulkuväylien liukkaudesta, kivistä, kannoista tai seipäistä. Myös rakennukset, rakenteet ja rakennelmat, kuten portaat ja lattia osoittautuivat vaaran ja tapaturmien aiheuttajiksi. Kaikkiaan tapaturmista noin $4 \%$ aiheutui edellä mainituista tekijöistä. Kuljetusajoneuvot, kuten traktorit, kuorma-autot ja moottoripyörät sekä hevosajoneuvot ja reet, peräkärryt ja moottorikelkat aiheuttavat osan tapaturmista. Muut koneet ja laitteet, muun muassa ruokintalaitteet ja hitsauslaitteet sekä vinssit, ruohonleikkuri ja pora aiheuttivat muutamia tapaturmia.

Suurin osa loukkaantumisista tapahtui sekä naisille että miehille eläinten valjastuksessa, siirrossa ja kuljetuksessa. Nämä työtehtävät aiheuttivat miehille $24 \%$ ja naisille $19 \%$ tapaturmista (Kuva 2). Toiseksi eniten loukkaantumisia aiheuttivat ravitoiminnat, kuten ratsastus, ajolle opetus ja valmennus. Miehille ravitoiminnat olivat syynä $12 \%$ :ssa ja naisille $7 \%$ :ssa tapaturmista. Miehille kolmanneksi eniten loukkaantumisia sattui harjauksessa, puhdistuksessa, kengityksessä, lääkityksessä, astutuksessa, varsomisessa ja tarkkailussa (9\%). Naisille puolestaan kolmanneksi eniten tapaturmia (6 \%) sattui rehun käsittelyssä, ruoan valmistuksessa ja ruokinnassa.

Hevostapaturmista noin $31 \%$ oli vakavia tapaturmia, eli tapaturma aiheutti vähintään 31 vuorokauden sairausloman. Suurin osa näistä vakavista tapaturmista sattui nimenomaan hevosten valjastuksessa, siirroissa sekä kuljetuksissa, ja suurin osa vammoista oli sijoiltaan menoja, nyrjähdyksiä ja venähdyksiä. Toiseksi eniten vakavia tapaturmia tapahtui ravitoiminnoissa, ratsastuksessa, ajolle opetuksessa ja valmennuksessa. Myös suurin osa lievistä tapaturmista tapahtui hevosten valjastuksessa, siirroissa ja kuljetuksissa.

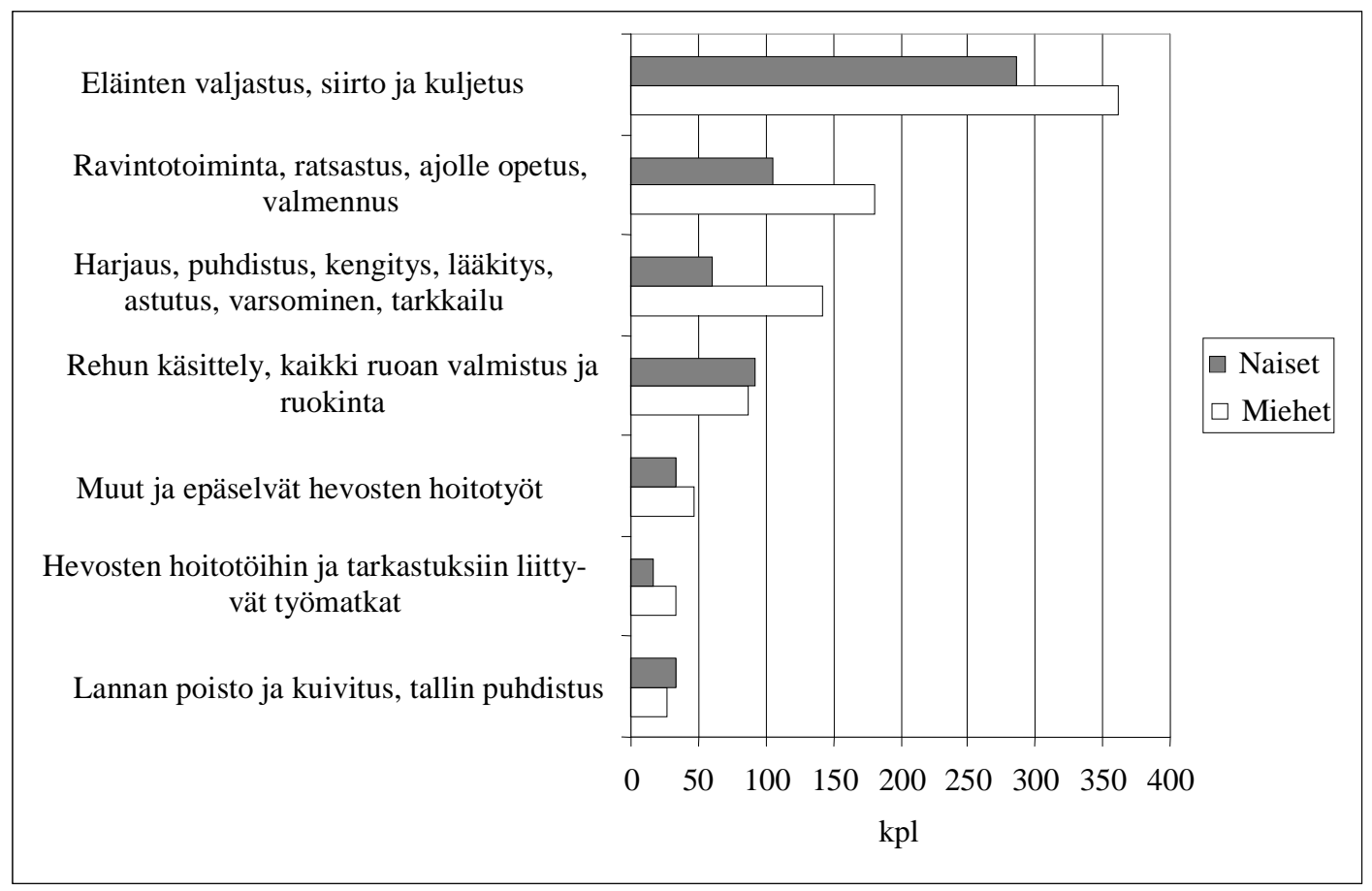

Kuva 2. Eri hevosenhoitotöissä tapahtuneiden tapaturmien määrät.

Hevostapaturmissa aiheutuneet yleisimmät vammat olivat naisilla ja miehillä sijoiltaan menoja, nyrjähdyksiä ja venähdyksiä. Niiden osuus tapaturmista oli noin $32 \%$. Tärähdyksiä ja sisäisiä vammoja oli kaikista tapaturmista noin $28 \%$ sekä luunmurtumia oli $22 \%$. Haavojen osuus oli $20 \%$. Lisäksi aiheutui muutamia tulehduksia, palovammoja, paleltumisia sekä syöpymiä. Myös raajojen irtirepeämisiä ja amputoimisia oli tapahtunut tämän tarkastelujakson aikana, mutta ne olivat yksittäistapauksia. Hevostapaturmissa yleisimmin sekä miehillä että naisilla loukkaantuivat ala- ja yläraajat (Kuva 3). Naisilla noin $10 \%$ ja miehillä $14 \%$ vammoista kohdistui vartalon, sisäelimien, rintakehän ja lapaluiden seudulle. Yhtä paljon vammoja tuli myös selkään, selkärankaan ja nikamiin. 
Ravitoiminnassa tapaturmien ja loukkaantumisten määrät hieman lisääntyivät viikonloppua kohden, mutta muissa hevosen hoitotöissä loukkaantumisia sattui tasaisesti pitkin viikkoa.

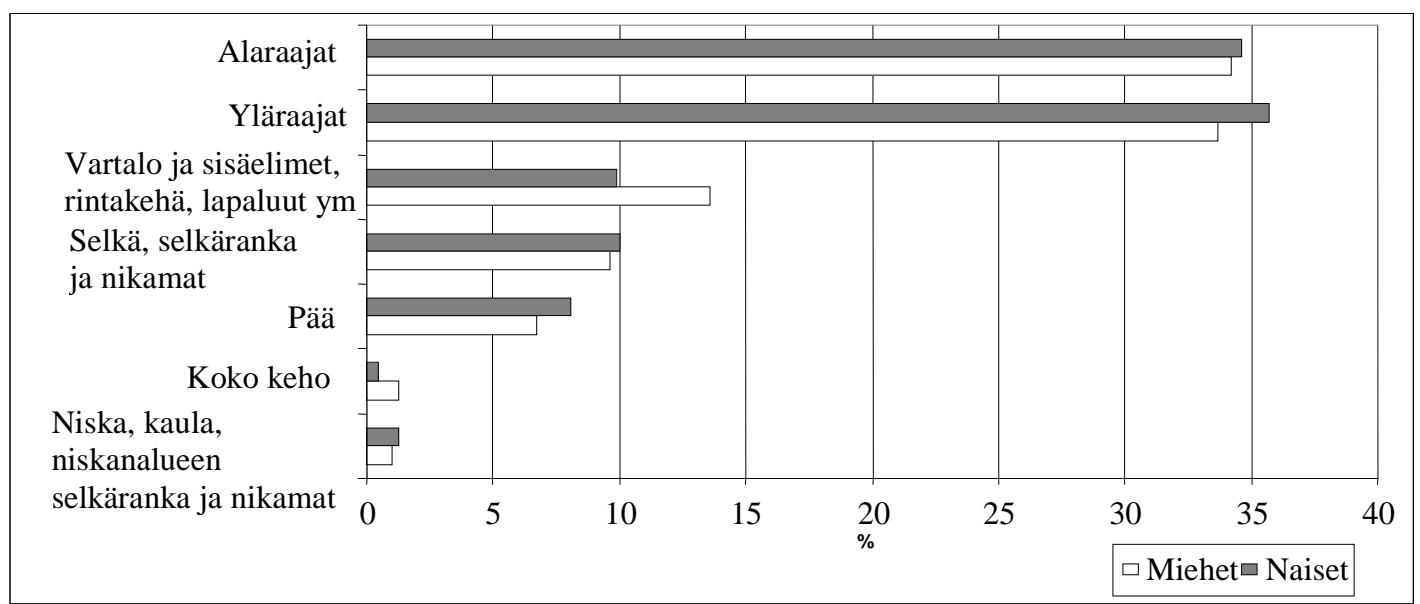

Kuva 3. Hevostapaturmien jakautuminen eri kehon osien välillä.

Hevostapaturmissa loukkaantuneista $58 \%$ oli miehiä ja suurin osa heistä oli 51-60 -vuotiaita. Naisista puolestaan loukkaantuivat yleisimmin 31-40 -vuotiaat. Vähiten loukkaantumisia tapahtui nuoremmissa ikäluokissa. Nuorilla ja vanhemmilla hevosenhoitajilla loukkaantumiset tapahtuivat hieman erilaisissa hoitotöissä. 15-20-vuotiaille hevosenhoitajille sattui noin puolet tapaturmista ravitoiminnassa, ratsastuksessa, ajo-opetuksessa ja valmennuksessa (Kuva 4). Ikäluokissa 21-70vuotiaat, keskimäärin $43 \%$ tapaturmista tapahtui eläinten valjastuksessa, siirrossa ja kuljetuksessa. Suurin osa vanhimmista hevosenhoitajista puolestaan loukkaantui rehun käsittelyssä, ruoan valmistuksessa ja ruokinnassa. 


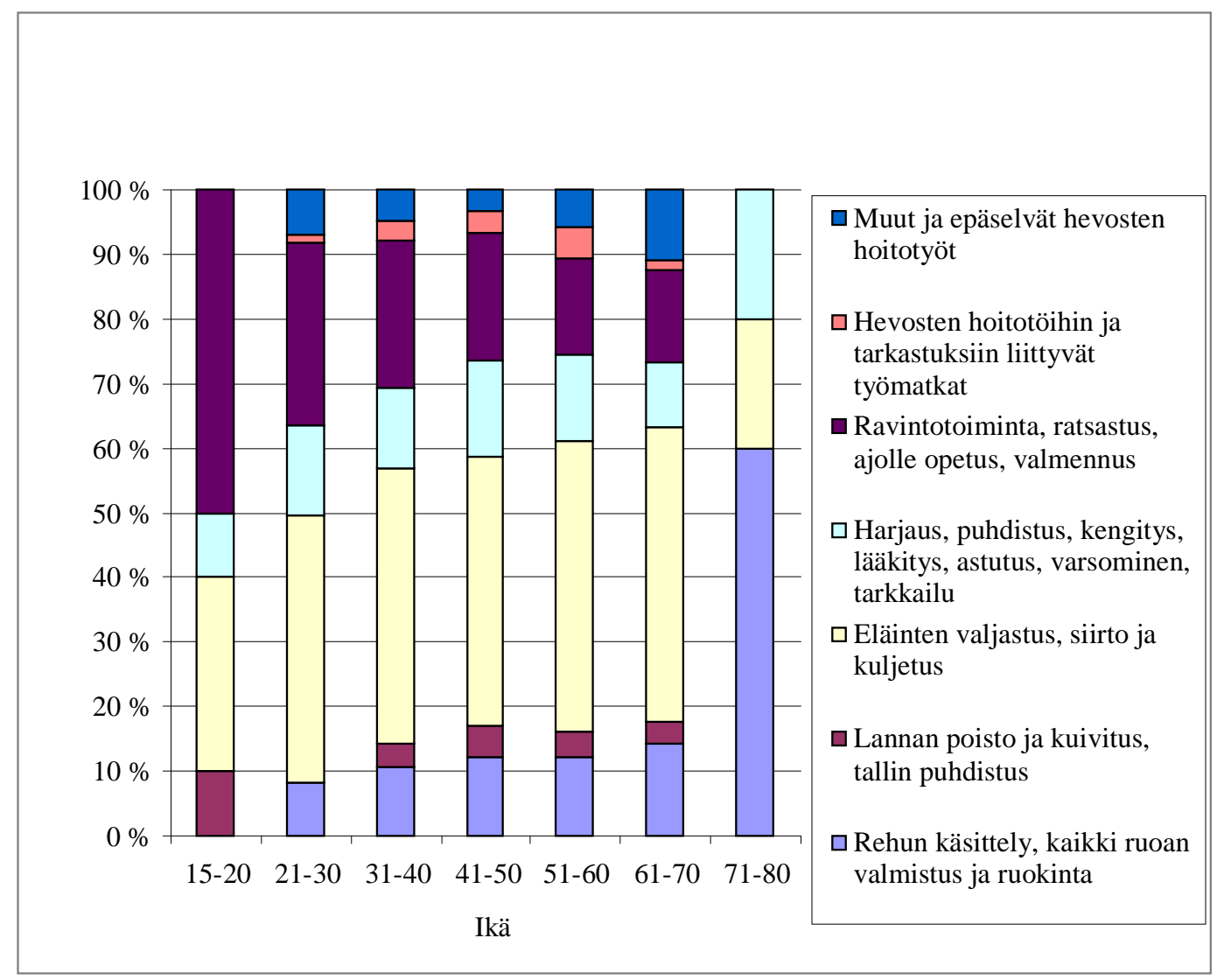

Kuva 4. Eri työvaiheissa loukkaantuneiden henkilöiden prosenttiosuudet ikäluokittain.

\section{Tulosten tarkastelu}

Noin $75 \%$ :ssa hevostapaturmista oli vamman aiheuttajana hevonen. Perussyy useimpiin hevosonnettomuuksiin on hevosen pakoreaktio. Hevosen luottamus ihmiseen on perusedellytys turvalliselle toiminalle hevosen kanssa (Bayley 2005). Vaaratilanteiden ennakoinnissa ja riskien vähentämisessä auttaa hevosen aistien tuntemus ja käyttäytymisen ymmärtäminen. Ammatikseen hevosten kanssa työskentelevä osaa ottaa huomioon nämä asiat. Hevosmäärän kasvaessa kasvaa myös kokemattomien hevosharrastajien määrä, eivätkä he välttämättä osaa tulkita hevosen antamia viestejä. Vaaratilanteita aiheuttaa ihmisen oma käytös, koneet, liikenne ja melu. (Pimiäinen 2005). Hevosen koulutusta ja tarkkailua lisäämällä sekä oman käytöksen rauhallisuutta ja kiireettömyyttä korostamalla (Jansson 2007) voi hevosen aiheuttamia tapaturmia ennaltaehkäistä.

Toiseksi suurin vammojen aiheuttaja hevostapaturmissa oli ulkoinen ympäristö. Tallin ulkopuolella pitää huolehtia kulkureittien turvallisuudesta ja hyvästä valaistuksesta. Talviaikana auraus ja liukkauden torjunta sekä hyvät jalkineet estävät useita liukastumisia ja kaatumisia. (Pimiäinen 2005). Lisäksi työympäristön turvallisuutta lisäävät siisteys, järjestys sekä toimivat ja tilavat työtilat. Tallin ja karsinoiden ovien tulee olla vähintään $150 \mathrm{~cm}$ leveitä, jotta ihminen ja hevonen pystyvät kulkemaan niistä yhtä aikaa turvallisesti. (Hirvonen ym. 2007). Tallissa liikkuvat henkilöt pitää opastaa tallin toimintoihin ja hevosten käsittelyyn. Lisäksi henkilöt, jotka osallistuvat hevosten ulkoiluttamiseen, tulee perehdyttää käyntiympäristöön hyvin. Hevosten ja talliympäristön tutuksi tekeminen vähentää virheitä, ongelmia ja epävarmuutta sekä tapaturmariskejä. Työturvallisuuskeskukselta löytyy opastamiseen tarkistuslista, josta selviää tallissa työskenteleville tärkeimmät työturvallisuuteen vaikuttavat tekijät. (Pimiäinen 2005).

Hevonen on luontaisesti avoimien maastojen eläin, joten sille on ominaista välttää ahtaita paikkoja (Kaimio 2004). Hevosen lastausta kuljetusautoon saattaa hankaloittaa hevosen aikaisemmat huonot kokemukset kuljetuksista tai luontainen kammo ahtaisiin paikkoihin. Lastaaminen on hevoselle 
stressaava tapahtuma (Kaimio 2004), joten sitä tulee opetella (Nieminen 2003). Varsana hyvin opetettu lastaus- ja kuljetustilanne on osa työturvallisuutta. Kuljetuksiin pitää varata riittävästi aikaa, jotta ihmisen hermoilu ei tartu hevoseen. Turvajalkineet hevosen käsittelijällä suojaavat polkeutumilta ja käsineet suojaavat narujen hiertymisiltä. Lastaussillan nosto ja avaus pitää tapahtua aina sivusta. Jos hevonen pelkää kuljetusta, sen rauhoittaminen lääkkeillä ei ole suositeltavaa. Lääkkeet eivät estä pelkoreaktiota, vaan nostavat reaktiokynnystä. Rauhoitetun hevosen käytös on hankalampi ennakoida kuin rauhoittamattoman. Rauhoitettu hevonen voi myös tahattomasti loukata itseään ja ihmisiä, sekä sen tasapaino on huonompi kuljetuksessa. Rauhoittavilla lääkkeillä hevonen ei opi käyttäytymään rauhallisesti. (Kaimio 2004).

Hevosen valjastus kuului myös tapaturma-alteimpiin hevosenhoitotöihin. Hevosta valjastetaan lähes päivittäin ja hevosten määrän lisääntyessä noin 1000:lla vuodessa, tulee joka vuosi 1000 valjastettavaa lisää. Hevosen häiriökäyttäytymistä aiheuttaa liikunnan puute, mutta myös sopimattomat varusteet. Jos päivittäin hevoselle laitetaan sopimattomat valjaat, jotka hiertävät ja aiheuttavat kipua, niin varmasti hevonen alkaa vastustaa valjastusta. (Lehtonen 2008). Tällöin tapaturmariski kasvaa. Yleisesti vahinkoja sattui myös ravitoiminnoissa, ratsastuksessa, ajolle opetuksessa ja valmennuksessa. Harrastehevoset ovat yleisesti myös kilpahevosia, joita valmennetaan säännöllisesti, joten näitä toimintoja tehdään päivittäin. Ratsastusonnettomuuksiin vaikuttaa myös ratsastusharrastuksen yleisyys. Suomessa ratsastuksen harrastajien määrä on 140000 ja se on viimeisen kymmenen vuoden aikana yli kaksinkertaistunut (Lehtonen 2008). Ratsastuksen turvallisuuden lähtökohta on ratsastajan ja hevosen yhteensopivuus. Hevosen kyvyt ja omat taidot pitää huomioida. Aloitteleva hevosharrastaja tekee joskus virheen ostaessaan edullisesti entisen kilpailu-uran lopettaneen ravihevosen ratsuksi. Ravihevosella voi ratsastaa kokenut ratsastaja, mutta se ei ole turvallinen ja rauhallinen ratsastusharrastusta aloittelevan henkilön ratsu. (Andersson \& Lindberg 2003). Ratsastajan turvavälineisiin kuuluvat kypärä, turvaliivi, käsineet, ratsastukseen sopivat jalkineet, jotka eivät jää jalustimeen kiinni sekä satulassa turvajalustimet. (Pimiäinen 2005). Ratsastustapaturmissa vahingoittuu usein selän alue ja selkäranka. Ratsastaessa turvaliivin käyttö ehkäisee selkävammoja.

Työntekijän pitää muistaa oikeat työasennot ja -liikkeet. Itse aiheutetut vammat vähenevät, kun muistaa pitää selän suorana nostoissa, välttää kiertoliikkeitä ja nostot tulee tehdä jaloilla eikä selällä. Itsensä kuormitusta voi vähentää käyttämällä siirtämisessä apuvälineitä, muuttamalla nostaminen ja kantaminen työntämiseksi ja vetämiseksi. (Pimiäinen 2005). Työn tekeminen hyvillä työvälineillä helpottaa työntekoa. Hyvät, tukevat ja kevyesti lykättävät lantakärryt helpottavat lannanluontia, sekä oikean pituiset talikon, lapion ja harjan varret säästävät selkää. Työntekijän työtä helpottavat myös lantalan sijainti lähellä tallia ja talvisin sulana olevat kuiviketarvikkeet. (Karttunen 2005).

\section{Johtopäätökset}

Hevostapaturma on usein monen tapahtuman yhdistelmä. Hevostapaturmien ehkäisyyn voi vaikuttaa hevosen ominaisuuksiin tutustumalla ja koulutuksella. Suunnittelulla ja turvallisuutta lisäävillä toimenpiteillä pystytään ympäristön riskitekijöitä vähentämään, mutta ulkopuolisten hevosen käytöstä ymmärtämättömien ihmisten toimintaan on hankalampi vaikuttaa. Hevonen toimii vaistojen ja kokemusten varassa. Ihmisen vastuulla on riskitilanteiden ja vaarojen havaitseminen sekä niiden poistaminen. Hevosten kanssa tapaturmariskiä voi vähentää opettelemalla hevosen luontaista käyttäytymistä ja tunnistamalla sen elekieli.

Hevostilan turvallisuutta voi myös parantaa liittymällä maatilatalousyrittäjien työterveyshuoltoon. Tähän kuuluu maksuton tilakäynti, jossa kartoitetaan tilan työolosuhteet ja tehdään tilalla terveysvaaroja ehkäiseviä parannusehdotuksia (Maatalousyrittäjien eläkelaitos 2008). Tilakäyntiin sisältyy hevostilan tapaturmariskien kartoitus, työergonomia, fysikaaliset sekä kemialliset haitat, ensiaputaito, henkilösuojainten tarve ja käyttö (Karttunen 2005). 


\section{Kirjallisuus}

Andersson, I. \& Lindberg, C. 2003. Uusi hevosenomistajan käsikirja. Hämeenlinna: Karisto Oy.

Bayley, L. 2005. Mitä hevoseni ajattelee. Helsinki: Kustannusyhtiö Tammi.

Hirvonen, P. Hyyppä, S. Jansson, H. Laine, P. \& Saastamoinen, M. 2007. Hevosen ruokinta ja hoito. Porvoo: WS Bookwell Oy.

Jansson, H. 2007. Hevosta ymmärtämällä voi välttää vaaratilanteita. Pro Hevonen 91 (4) 64-67.

Kaimio, T. 2004. Hevosen kanssa. Porvoo: WSOY.

Karttunen, J. 2005. Vakavat työtapaturmat maatiloilla. Loimaa:Priimuspaino Oy.

Lehtonen, S. 2008. Hevosta ei pidä hankkia ilman tarkkaa hankintaa ja osaamista. Maaseudun tulevaisuus. 21.4.2008

Nieminen, V. 2003. Hevosen käsittely ja käyttäytyminen. Helsinki: Art House Oy.

Niiranen, R. 2008. Hevosten lukumäärä kasvaa edelleen. Maaseudun tulevaisuus. 7.4.2008.

Pimiäinen, K. 2005. Hevoset ja työturvallisuus. IS-Print.

Tiilikainen, S. 2004. Hevostalous maatiloilla. MTT:n selvityksiä 67.

Maatalousyrittäjien eläkelaitos. 6.5.2008. Esittely. [www-dokumentti].

$<$ http://www.mela.fi/Sisaltosivu.aspx?path=172,126,588 $>$.

Suomen Hippos ry. 11.2.2008 Hevoskannan kehitys maassamme 1910-2005. [www-dokumentti]. <http://www.hippos.fi/hippos/tilastot/jalostus_ja_kasvatus/hevoskannan_kehitys.php $>$ 